OPEN ACCESS

Edited by:

Alexander Nikolaevich Orekhov, Institute for Aterosclerosis Research

(Russia), Russia

Reviewed by: Veronika Myasoedova, Monzino Cardiology Center (IRCCS), Italy Evgeny Bezsonov,

Russian Academy of Medical Sciences, Russia

*Correspondence:

Feng Chen

cy.chen508@gmail.com

†These authors have contributed equally to this work

Specialty section:

This article was submitted to Atherosclerosis and Vascular

Medicine,

a section of the journal Frontiers in Cardiovascular Medicine

Received: 23 February 2021 Accepted: 22 March 2021 Published: 16 April 2021

Citation:

Zeng $Y$ YY, Zhang $M$, Ko S and Chen F (2021) An Update on Cardiovascular Risk Factors After Kawasaki Disease. Front. Cardiovasc. Med. 8:671198

doi: $10.3389 /$ fcvm.2021.671198

\section{An Update on Cardiovascular Risk Factors After Kawasaki Disease}

\author{
Yuan-Yuan Zeng ${ }^{1+}$, Min Zhang ${ }^{2 t}$, Syeun $\mathrm{Ko}^{3}$ and Feng Chen ${ }^{1 *}$ \\ ${ }^{1}$ Department of Pharmacy, Children's Hospital of Nanjing Medical University, Nanjing, China, ${ }^{2}$ Department of Pharmacy, \\ Boston Medical Center, Boston, MA, United States, ${ }^{3}$ School of Pharmacy, Northeastern University, Boston, MA, \\ United States
}

First described in Japan 50 years ago, Kawasaki disease is a worldwide multisystem disease. It is an acute self-limited vasculitis of unknown etiology that can lead to coronary artery lesions, such as dilatation, aneurysms, and stenosis in children. It is one of the common causes of acquired heart disease among children in developed countries. The coronary aneurysm is a severe complication in the acute stage, possibly leading to stenotic lesions or myocardial ischemia. More concerns have centered on endothelial damage and the early onset of atherosclerosis in patients with KD. Although the coronary artery aneurysm is small or degenerated, the vascular structure does not return to normal, vascular endothelial dysfunction and remodeling continue. Most patients diagnosed with coronary artery sequelae are at risk of long-term complications. There are still many unknown aspects regarding the long-term prognosis of patients. Concerns have centered on the early onset of atherosclerosis in patients with $\mathrm{KD}$. There is still no consensus on the relationship between Kawasaki disease and atherosclerosis. This study aimed to evaluate if patients with a history of KD were at risk of accelerated atherosclerosis.

Keywords: Kawasaki disease, atherosclerosis, long-term management, cardiovascular risk factors, endothelial dysfunction, multisystem inflammatory syndrome

\section{INTRODUCTION}

Kawasaki disease $(\mathrm{KD})$ is a form of idiopathic vasculitis that affects small- or medium-sized vessels throughout the body, and often the coronary arteries (1). It is considered the leading cause of acquired heart disease among children living in developed countries (2). Early diagnosis and treatment of $\mathrm{KD}$ have reduced the incidence of coronary artery abnormalities (CAAs) from $\sim 25$ to 5\% (3). Apart from CAAs, children with KD are also prone to develop endothelial dysfunction $(4,5)$, arterial stiffening $(6,7)$, and a proatherogenic lipid profile (8). Although there is sufficient data on CAAs related to $\mathrm{KD}$, data on long-term complications of $\mathrm{KD}$, especially atherosclerosis, remain limited. In the late-stage of $\mathrm{KD}$, markers of atherosclerosis such as endothelial dysfunction, oxidative stress, elevated levels of high-sensitivity C-reactive protein (hsCRP)/C-reactive protein (CRP), and inflammatory cytokines have been reported (9-13). The accumulating data suggests that patients with $\mathrm{KD}$ history may be at risk of developing premature atherosclerosis. The American Heart Association (AHA) guidelines in 2004 (14) stratified patients with KD according to their relative risk of myocardial ischemia and recommend monitoring those with extensive CAA or coronary artery obstruction for known risk factors of atherosclerosis. The updated AHA 2017 guidelines (15) modified the risk stratification criteria by incorporating different risk levels based on past and current coronary artery involvement and adjusting for body size, which the 
previous guidelines did not address. In this study, we sought to provide updates on the profile of cardiovascular risk factors in $\mathrm{KD}$ patients after the acute illness.

\section{EPIDEMIOLOGY OF KD}

It has been reported from more than 60 countries after the first description in Japan (16). Based on a Japanese national (17), the number of KD patients has increased annually from 1995 to 2015 . The frequency of atypical KD has increased from $9.8 \%$ in 1992 to $20.6 \%$ in 2016 . The prevalence among 100,000 children aged 0-4 years was 319.6 in Japan, 170.9-194.9 in Korea, 71.9-110.0 in China, 49.4 in Hawaii, and 18.1-21.3 in the USA (18). The incidence was highest among Asian children, especially of Japanese ancestry. A 2006 USA survey (19) comprising $5,523 \mathrm{KD}$ patients found that the incidence was higher in boys vs. girls (24.2 per 100,000 vs. 16.8 per 100,000 , respectively). With the SARS-CoV-2 coronavirus pandemic, an increased number of children presenting with a novel syndrome sharing the features of $\mathrm{KD}$ and toxic shock syndrome, now named Multisystem inflammatory syndrome in children (MIS-C). Common overlapping clinical symptoms of MIS-C and KD include conjunctivitis, rash, red eyes, swollen hands and feet, red/cracked lips, swollen glands. Children with MIS-C had a broader age range, a deranged coagulation profile, significant gastrointestinal and neurologic symptoms. The laboratory findings also revealed significant elevation of cardiac and inflammatory markers, including Troponin, pro-Btype natriuretic peptide (proBNP), C-reactive protein (CRP), and erythrocyte sediment rate (ESR). Epidemiologic studies of MIS$\mathrm{C}$ have suggested that younger children are more likely to present with KD-like features while older children are prone to develop myocarditis or myocardial dysfunction (20-26). Cardiovascular complications in the acute phase of $\mathrm{KD}$ were reported in $9.2 \%$ (10.2\% of boys and $7.7 \%$ of girls) of patients in Japan's 25 th national survey (27). Cardiovascular complications included coronary dilatation (6.52\%), valvular lesions (1.55\%), coronary aneurysms $(0.95 \%)$, giant coronary aneurysms $(0.11 \%)$, coronary stenosis (0.02\%), and acute myocardial infarction (AMI) (0.01\%). Cardiovascular sequelae reported in $2.76 \%(3.17 \%$ of boys and $2.26 \%$ of girls) of patients, included coronary dilatation $(1.5 \%)$, coronary aneurysms $(0.63 \%)$, valvular lesions $(0.5 \%)$, giant coronary aneurysms $(0.11 \%)$, coronary stenosis $(0.02 \%)$, and myocardial infarction (MI) $(0.003 \%)$. Except for valvular lesions, these sequelae occurred more often in boys. In addition,

Abbreviations: ACC, American College of Cardiology; ACEI, angiotensin II receptor blocker; ACS, acute coronary syndrome; AHA, American Heart Association; AMI, acute myocardial infarction; Ang II, angiotensin II; ARB, angiotensin converting enzyme inhibitor; CAAs, coronary artery abnormalities; CALs, coronary artery lesions; cIMT, Carotid intima-media thickness; CRP, C-reactive protein; CVD, cardiovascular disease; FMD, flow-mediated dilatation; hsCRP, high-sensitivity C-reactive protein; HDL, high-density lipoprotein; HDL-C, high-density lipoprotein cholesterol; IL, interleukin; IVIG, intravenous immunoglobulin; JCS, Japanese Circulation Society; KD, Kawasaki disease; LDL, low-density lipoprotein; LDL-C, low-density lipoprotein cholesterol; MI, myocardial infarction; MMPs, matrix metalloproteinases; NMR, nuclear magnetic resonance; RAS, renin-angiotensin system; TC, cholesterol; TG, triglycerides; TNF, tumor necrosis factor; \%FMD, the percent flow-mediated dilatation. the incidence of coronary aneurysms and coronary dilatation was higher in patients with atypical KD. The frequency of cardiac sequelae from the annual survey in Japan is shown in Figure 1 (17).

\section{THE PATHOLOGY OF KD}

\section{Causes and Pathogenesis}

The cause of $\mathrm{KD}$ remains unknown. It is speculated that this disease may be triggered by a novel RNA virus that enters through the upper respiratory tract, which leads to pathogen-induced immune response (28, 29). Researchers had found intracytoplasmic inclusion bodies of RNA virus in multiple cells throughout the KD patients' body. However, the molecular details of these inclusion bodies remain unknown. Epidemiological studies suggested that $\mathrm{KD}$ might be caused by conventional pathogens ranging from gram positive or atypical microorganisms (30). Activation of the immune system with high numbers of activated neutrophils, interleukin (IL)-1, IL-6, and tumor necrosis factor (TNF) was found in $\mathrm{KD}$ patients (31). Activated monocytes/macrophages seem to play an essential role in $\mathrm{KD}$ (31-33), which stimulate inflammatory cells to infiltrate and accumulate in the intima, and release proinflammatory molecules including IL-1, IL-6, TNF $\alpha$, and matrix metalloproteinases (MMPs). Neutrophils elastase is released, which damages the internal elastic lamina and causes thickening. Macrophages secrete the inducible nitric oxide synthase (iNOS). This cascade of events leads to intimal proliferation, internal elastic destruction, and aneurysmal dilatation of the vessel (Figure 2) (34).

\section{Formation and Progress of Coronary Artery Aneurysms}

In the early stages of $\mathrm{KD}$, the synchronous neutrophilic process involving necrotizing arteritis is complete within 2 weeks after fever onset. It progressively destroys the arterial wall into the adventitia, causing the coronary artery lesions (CALs) to dilate. The internal and external elasticity become fragmented, causing aortic blood pressure to become unbearably high, and an aneurysm begins to form (35). If the internal diameter of an aneurysm increases excessively, rupture, or thromboembolism may occur. After the acute phase of $\mathrm{KD}$, chronic vasculitis characterized by an asynchronous infiltration of plasma cells, lymphocytes, and eosinophils with decreased macrophages can continue for months or years in a small proportion of patients. At this phase, progressive thickening of the intima may lead to lumen stenosis. If clinical manifestations are evident, it can cause peripheral myocardial ischemia (Figure 3). Pathological outcomes of coronary artery aneurysms depend on the severity of the lesions. Slightly dilated arteries may have a chance to return to normal. Large or giant aneurysms have thickening intima and lost their elastica, which cannot be regenerated. Aneurysms and atherosclerotic lesions may occur in coronary artery branches (36). 

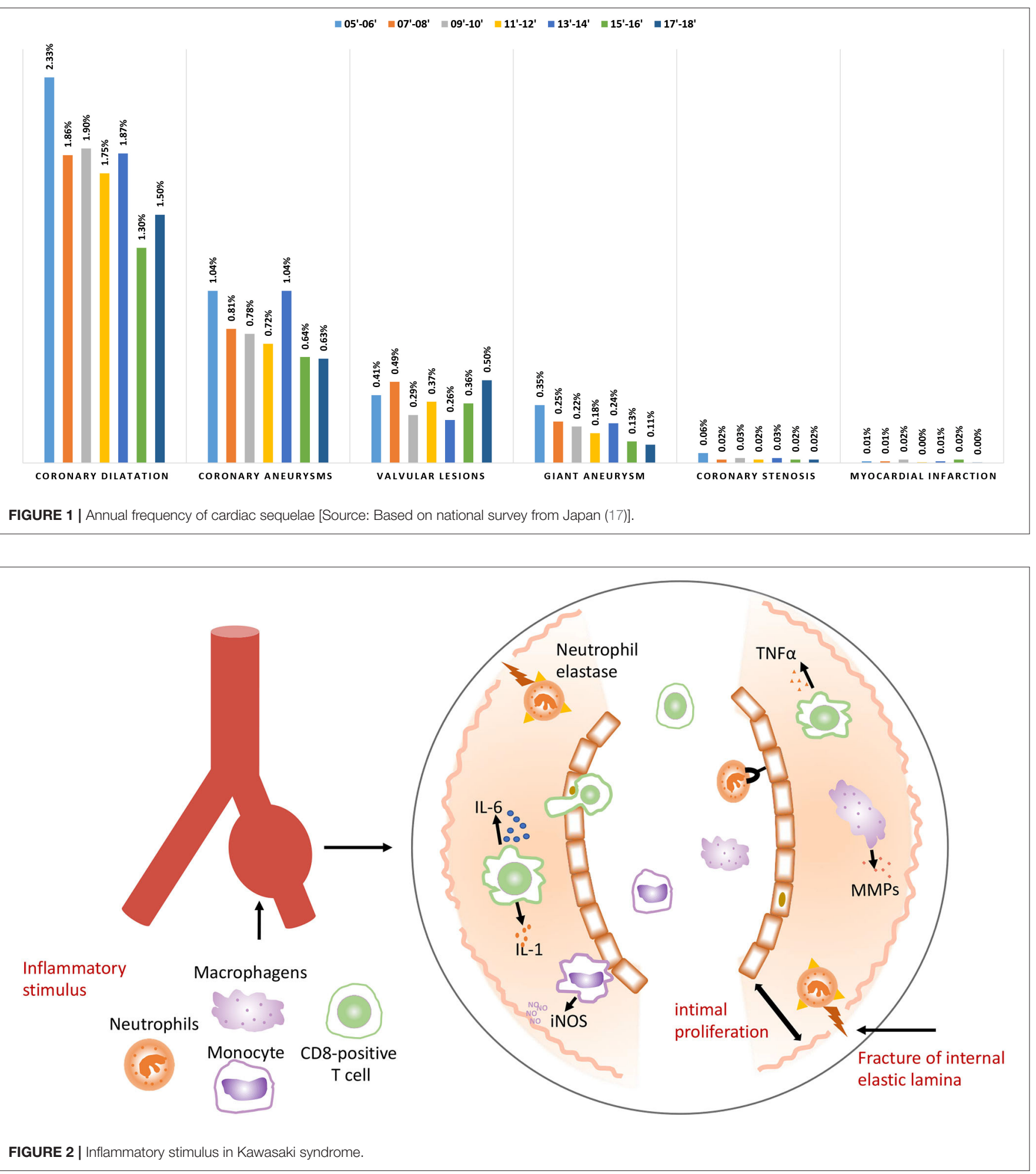

\section{Potential Mechanisms of Atherosclerosis Formation}

Carotid intima-media thickness (cIMT) $(37,38)$, abnormal lipid profile (39-41), including total cholesterol (TC), triglycerides (TG), low-density lipoprotein (LDL) cholesterol (LDL-C), arterial stiffness $(42,43)$, flow-mediated dilatation (FMD) (5) and inflammatory biomarkers [hsCRP (44) and, myeloperoxidase (45)] have been reported to be the risk factors for atherosclerosis. On the other hand, those markers mentioned earlier also appear in patients with $\mathrm{KD}$ history $(5,6,11,46)$. Potential mechanisms 


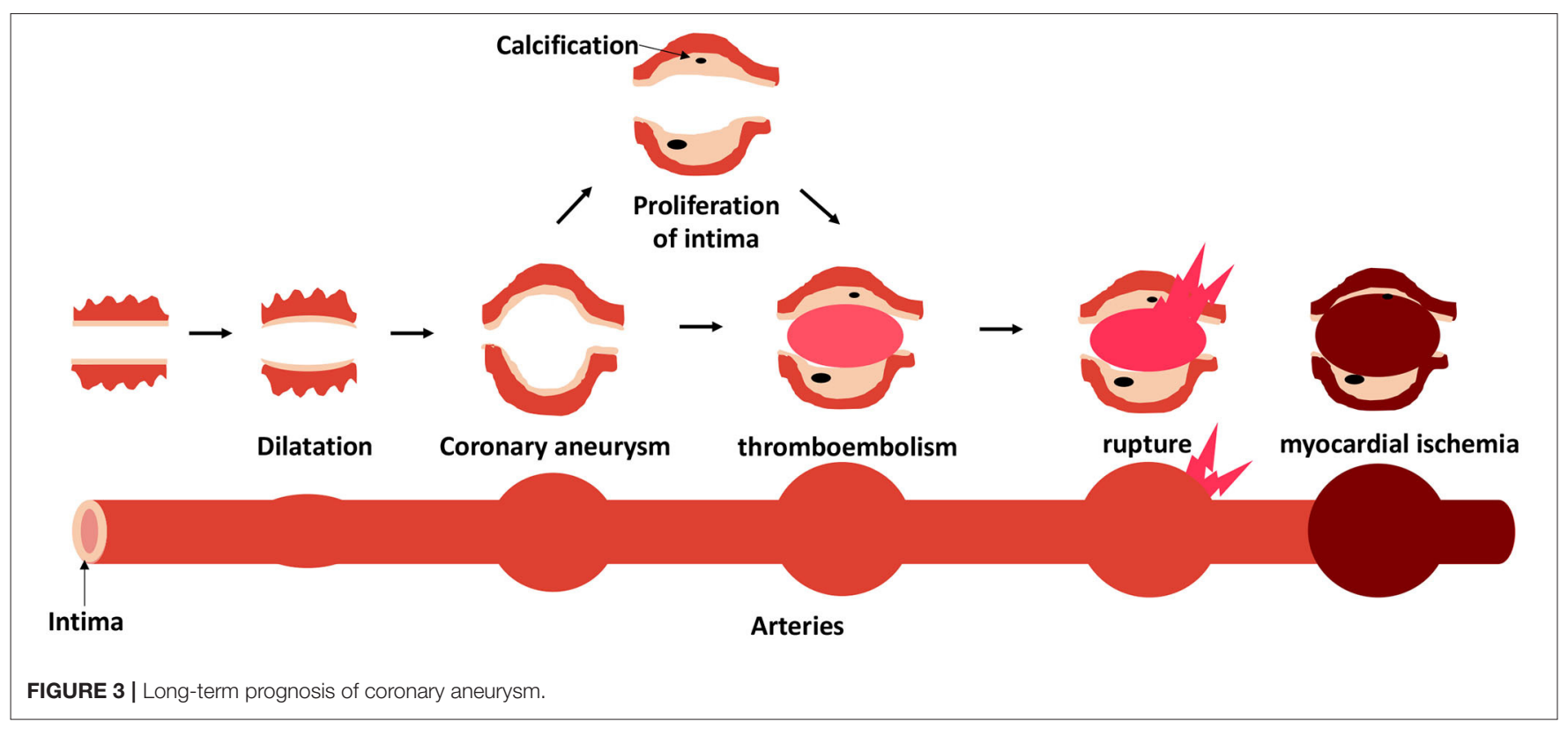

of increased risk for accelerated atherosclerosis include (1) arterial damage secondary to the acute process of the disease itself that may change the vascular structure and function, and propagate proatherogenic progress, (2) enduring inflammation and vasculitis that promote the development of atherosclerosis, and (3) patients with a history of KD may have other types of risk factors for atherosclerosis (47).

\section{CLINICAL POINT OF VIEW: NO CONSENSUS}

\section{Carotid Intima-Media Thickness}

The cIMT is a noninvasive marker of atherosclerosis (38), and is considered a useful marker in adults (48). Recent research has focused on cIMT to determine if patients with KD history may be at risk of premature atherosclerosis (Table 1) $(6,43,49-57)$. A few studies showed that the mean cIMT was significantly higher in KD patients than controls $(p<0.001)(6,49,52,56,57)$, while other studies did not show similar results $(43,50,51,53-55)$. Noto et al. (56) found significant differences between cases and controls, and in patients with $\mathrm{KD}$ history, atherosclerosis seemed to be age-dependent. The mean age of KD patients was 20.5 . However, 26 out of the 35 patients included had persistent CAAs, and only $52 \%$ had received intravenous immunoglobulin (IVIG) during the acute episode. Gopalan et al. (49) found that the mean cIMT remained higher in patients with KD than those without $\mathrm{KD}$ at an average duration of 6.9 years after the acute episode. The authors suggested that children with KD may continue to have increased cIMT even several years after the acute phase. Watanabe et al. (58) found similar results. Virtual histologicalintravascular ultrasonography findings were compared between patients with KD for $<1$ year (group A) and those with KD for $>10$ years (group B). There was no difference in the area percentage of atherosclerosis between the groups. However, the authors concluded that atherosclerotic-like findings exist in CAL in patients with $\mathrm{KD}$, even within a year of onset. Investigators (6) found intima-media thickening in patients with or without CAL and detected long-term functional abnormalities in KD patients with regressed CAAs or angiographically normal coronary arterial. Several studies $(51,53,55)$ did not find significant difference in cIMT between the patients with KD and controls given variations in the study population, consisting of a younger or older population or a small group of patients with giant aneurysms. The 2017 American AHA guidelines (15) and the 2020 Japanese JCS guidelines (18) used the coronary artery $Z$-scores to classify Kawasaki patients into five risk levels. The higher the risk level, the higher the likelihood of a cardiovascular event in the patient. The above-mentioned studies only described the presence of CAAs in patients but did not stratify them based on risk categories. This may be one of the reasons for various results between the studies. Including more high-risk patients with persistent CAAs would be more desirable to study the association of cIMT on disease severity.

\section{Flow Mediated Dilatation}

Vascular function test FMD can be measured and used as a noninvasive index of endothelial function (43). It uses ultrasound imaging to measure the arterial response during reactive hyperemia. Because of its noninvasive nature, FMD has recently been studied in KD patients (Table 2) $(4,5,43,51,56,59,60)$. Most of the studies achieve statistically significant results $(4,5$, $51,56,59)$. The percent FMD (\%FMD) was significantly reduced in the KD group than the control group. Two studies $(51,59)$ categorized the participants into three groups for comparisons, group 1 with CAA/CAL, group 2 without CAA/CAL, and group 3 comprised healthy controls. They found the \%FMD differed 
TABLE 1 | Studies on carotid intima-media thickness (CIMT) in patients with a history of KD.

\begin{tabular}{|c|c|c|c|c|c|c|c|c|c|c|}
\hline Author, year & Country & $N$ & Age & Male (\%) & Follow-up (years) & Persistent CAAs & cIMT (mm) & $P$ & Treat (\%) & Reference \\
\hline \multirow[t]{2}{*}{ Gopalan, 2018} & India & 27 & $13.85 \pm 2.75$ & 74 & $6.97 \pm 1.18$ & 0 & Cases: $0.54 \pm 0.087$ & $<0.001$ & 100 & (49) \\
\hline & & & & & & & Control: $0.42 \pm 0.036$ & & & \\
\hline & & & & & & & Control: $0.035 \pm 0.076$ & & & \\
\hline Chen, 2017 & Australia & 60 & 14.3 & 58 & $11.46 \pm 5.60$ & 15 & Cases: $0.49 \pm 0.05$ & 0.80 & 92 & (50) \\
\hline & & & & & & & Control: $0.433 \pm 0.028$ & & & \\
\hline \multirow[t]{2}{*}{ Meena, 2013} & India & 27 & $8.22 \pm 2.6$ & 74 & $2.45 \pm 1.19$ & 1 & Cases: $0.500 \pm 0.071$ & 0.000 & 100 & (52) \\
\hline & & & & & & & Control: $0.417 \pm 0.065$ & & & \\
\hline \multirow[t]{2}{*}{ Selamet Tierney, 2013} & America & 203 & $16.73 \pm 4.21$ & 60 & $11.6(1.2-26)^{\star}$ & 10 & Cases: $0.45 \pm 0.03$ & 0.385 & 93 & (53) \\
\hline & & & & & & & Control: $0.43 \pm 0.04$ & & & \\
\hline Lee, 2009 & & & & & & & Control: $0.50 \pm 0.01$ & & & \\
\hline \multirow[t]{2}{*}{ Noto, 2009} & Japan & 35 & $20.5 \pm 9.3$ & 80 & $18.6 \pm 8.4$ & 26 & Cases: $0.57 \pm 0.15$ & $<0.001$ & 52 & (56) \\
\hline & & & & & & & Control: $0.46 \pm 0.05$ & & & \\
\hline \multirow[t]{2}{*}{ Cheung, 2007} & China & 50 & $8.6 \pm 2.8$ & 66 & $6.6 \pm 3.1$ & 13 & Cases: $0.41 \pm 0.04$ & $<0.001$ & 90 & (6) \\
\hline & & & & & & & Control: $0.36 \pm 0.04$ & & & \\
\hline \multirow[t]{2}{*}{ Dalla Pozza, 2007} & Germany & 20 & $12.1 \pm 4.7$ & 60 & $4.1 \pm 3.6$ & NM & Cases: $0.45 \pm 0.02$ & $<0.001$ & 100 & (57) \\
\hline & & & & & & & Control: $0.42 \pm 0.01$ & & & \\
\hline
\end{tabular}

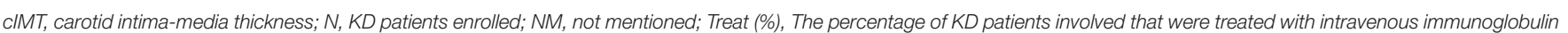
(IVIG) infusion \pm aspirin at the time of diagnosis; ' $m e d i a n$ (range).

TABLE 2 | Studies on flow-mediated dilatation (FMD) in patients with a history of KD.

\begin{tabular}{|c|c|c|c|c|c|c|c|c|c|c|}
\hline Author, year & Country & $N$ & Age & Male (\%) & Follow-up (years) & Persistent CAAs & $\%$ FMD & $P$ & Treat (\%) & Reference \\
\hline \multirow[t]{2}{*}{ Parihar, 2017} & India & 20 & $11.48 \pm 3.5$ & 60 & $4.48 \pm 1.88$ & 0 & Cases: $13.31 \pm 10.41$ & 0.874 & 100 & $(43)$ \\
\hline & & & & & & & Control: $12.86 \pm 7.09$ & & & \\
\hline & & & & & & & Cases 2: 9.1 & & & \\
\hline & & & & & & & Control: 13.9 & & & \\
\hline \multirow[t]{2}{*}{ Noto, 2009} & Japan & 35 & $20.5 \pm 9.3$ & 80 & $18.6 \pm 8.4$ & 26 & Cases: $9.1 \pm 2.7$ & $<0.001$ & 52 & $(56)$ \\
\hline & & & & & & & Control: $13.3 \pm 4.8$ & & & \\
\hline \multirow[t]{3}{*}{ Liu, 2009} & China & 41 & $7.15(3-11)^{\star}$ & 61 & $4.4(1.5-10)^{\star}$ & 21 & Cases 1: $4.5 \pm 1.5$ & $<0.01$ & 100 & (59) \\
\hline & & & & & & & Cases 2: $9.5 \pm 2.8$ & & & \\
\hline & & & & & & & Control: $12.1 \pm 2.3$ & & & \\
\hline & & & & & & & Control: $8.0 \pm 2.9$ & & & \\
\hline
\end{tabular}

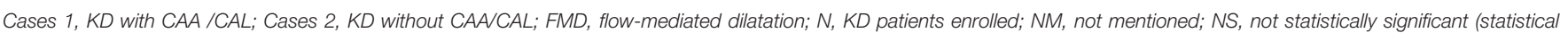

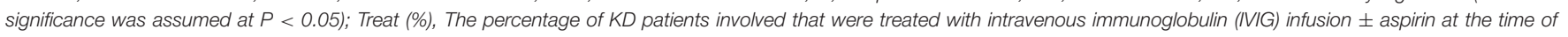
diagnosis; \%FMD: the percent FMD; " median (range).

significantly among the three groups. KD patients, especially those with CAA /CAL, would be more likely to have severe endothelial damage. Two studies $(43,60)$ found no significant differences between cases and controls. However, compared to others, they had few or no persistent CAAs in KD groups. The long-term complications remain low for patients without 
coronary artery involvement (15), similar to those without KD diagnosis (61).

\section{Lipid Profile}

Determination of lipid profile is a part of risk stratification for atherosclerosis. The protective role of high-density lipoprotein (HDL) and the pathogenic role of LDL, TC, and TG in atherosclerosis are well-established. Some investigators (Table 3) studied the lipid profile between $\mathrm{KD}$ patients and controls to determine the differences $(5,47,50,54,56,57,60,62,63)$. A majority of the existing studies indicated no differences between $\mathrm{KD}$ patients and controls on the lipid profile. However, one study (63) had a statistically significant result. The authors found that KD patients had significantly lower TC $(P<0.001)$, LDL $(P<0.001)$, and TG $(P=0.008)$ than those controls. Unlike other studies, the authors used nuclear magnetic resonance (NMR) spectroscopy to directly quantify the number of LDL and HDL particles and their size distribution because of its accurate assessment of atherosclerotic risk. The authors recommended managing KD patients with documented hyperlipidemia more proactively.

TABLE 3 | Studies on lipid profile in patients with a history of KD.

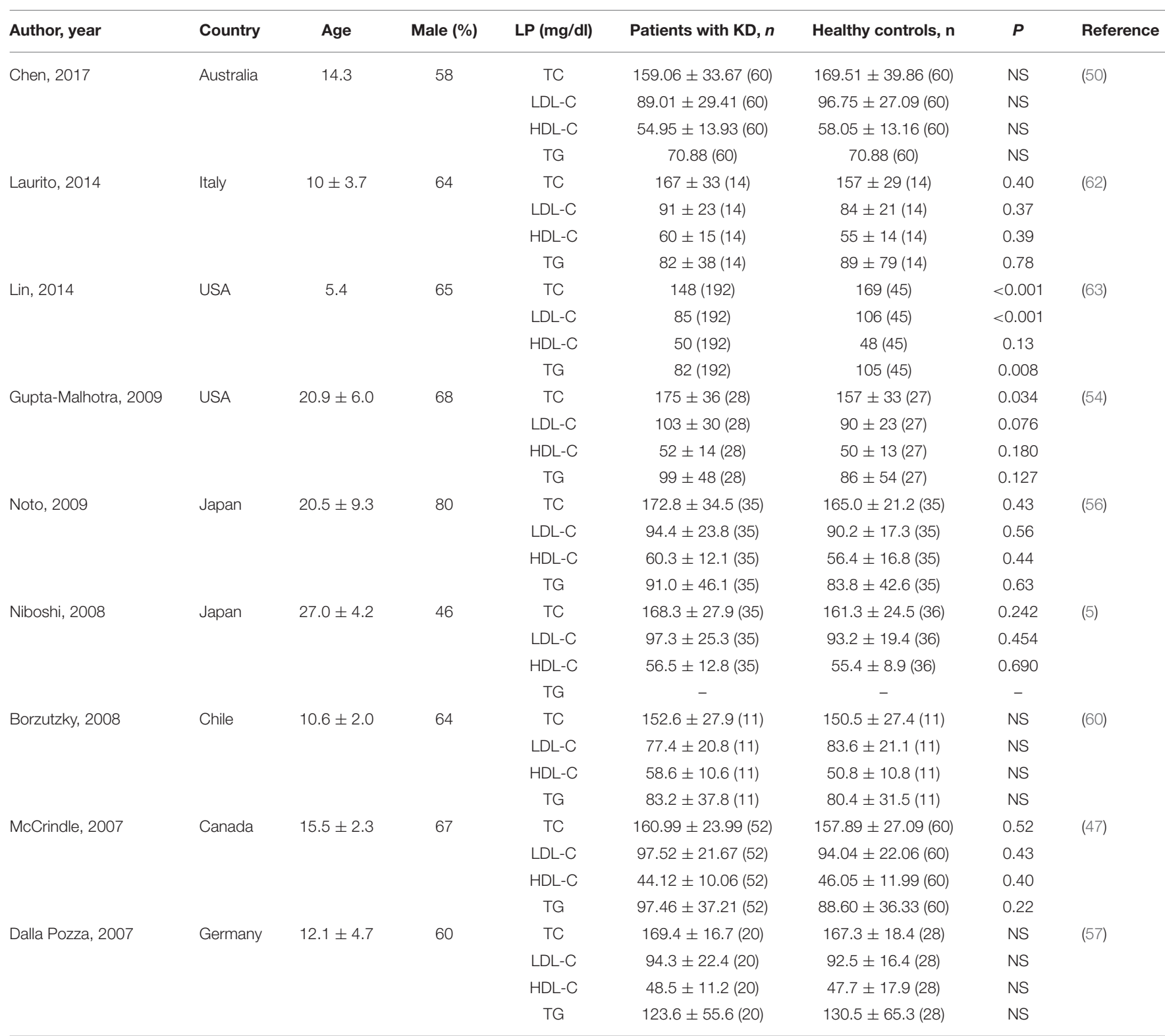

HDL-C, High-density lipoprotein cholesterol; LDL-C, low-density lipoprotein cholesterol; LP, lipid parameter; NS, not statistically significant (Statistical significance was assumed at P < 0.05); TC, total cholesterol; TG, triglycerides. 


\section{High-Sensitivity C-Reactive Protein or C-Reactive Protein}

Some studies support the role of the inflammatory mechanisms in atherogenesis $(44,64,65)$. Leukocyte recruitment and proinflammatory cytokines are crucially in the early phase of atherogenesis (44). Serum hsCRP, an indicator of inflammation, is a reliable clinical marker to predict the risk of coronary events (11). Several studies (Table 4) discussed (hs) CRP in followup patients of $\mathrm{KD}$ recent years $(5,42,50,51,54,57,60)$. The inflammatory process was more severe in $\mathrm{KD}$ patients with persistent CAL than those without, manifested with prolonged duration of fever and increasing CRP levels (51). The authors hypothesized the longer the duration of fever, the greater the risk of inflammation-induced endothelial dysfunction in $\mathrm{KD}$ patients. Another study showed similar result (57). Borzutzky et al. (60) found that patients with elevated hsCRP did not have persistent CAL, suggesting that inflammation may also be present in the large subgroup of children without persistent CAL. Niboshi et al. (5) found no statistically significant difference between cases and controls. The investigators classified the KD patients into three groups: group A with CAL; group B with transient CAL; and group $\mathrm{C}$ without CAL. The results revealed a significant increase in group $\mathrm{A}$ as compared to the control group. In contrast with aforementioned studies, several other studies $(42,50,54)$ had negative results. Cho et al. (42) revealed that levels of hsCRP were not significantly different between $\mathrm{KD}$ and healthy subjects, however, homocysteine level, another indicator of inflammation, was significantly higher in KD groups. And one of the studies that had negative results (54), compared to others, had no persistent CAAs in KD groups. Therefore, $\mathrm{CPR} / \mathrm{hsCRP}$ should not be used as the only inflammatory marker when examining patients with $\mathrm{KD}$. The combined use of several biomarkers would help predict association with disease severity and development of CAAs.

\section{LONG-TERM MANAGEMENT}

\section{Evaluation and Lifestyle Change}

It remains unknown if atherosclerotic risk factors affect the long-term progression of KD (15). Nonetheless, KD patients have been classified as a risk condition of atherosclerotic cardiovascular disease (CVD) and targeted in the evaluation of atherosclerotic CVD. KD patients with current coronary aneurysms are considered high risk, and those with regressed aneurysms are at moderate risk (66). Other risk factors include family history, age, gender, diet, physical inactivity, tobacco exposure, blood pressure, lipid levels, obesity, diabetes mellitus, predisposing conditions, metabolic syndrome, inflammatory markers and perinatal factors (66). Although it is challenging to recognize the progression of atherosclerosis in patients with $\mathrm{KD}$ history, coronary endothelial dysfunction seems to be present in those with CAL. A recent scientific statement from the Japanese Circulation Society (JCS) (18) recommends eliminating arteriosclerosis-promoting factors in patients with CAL, and lifestyle modifications including smoking cessation, prevention of obesity, and healthy diet, are essential for patients with KD history.

\section{Medical Treatment of CAL Statins}

Statins have been the cornerstone of therapy for preventing atherosclerotic cardiovascular events in adults (67). Based on the American College of Cardiology (ACC)/AHA Guidelines for the primary prevention of cardiovascular disease, statin

TABLE 4 | Studies on C-reactive protein (CRP)/high-sensitive C-reactive protein (hsCRP) in patients with a history of KD.

\begin{tabular}{|c|c|c|c|c|c|c|c|c|c|c|}
\hline Author, year & Country & $N$ & Age & Male (\%) & Follow-up (year) & $\begin{array}{c}\text { Persistent } \\
\text { CAAs }\end{array}$ & (hs)CRP (mg/dl) & $P$ & Treat (\%) & Reference \\
\hline \multirow[t]{2}{*}{ Chen, 2017} & Australia & 60 & 14.3 & 58 & $11.46 \pm 5.60$ & 15 & Cases: $0.06^{\star}$ & NS & 100 & $(50)$ \\
\hline & & & & & & & Control: $0.04^{*}$ & & & \\
\hline \multirow[t]{3}{*}{ Cho, 2014} & Korean & 68 & $7.61 \pm 1.69$ & 59 & $5.05 \pm 2.43$ & 8 & Cases 1: $0.91 \pm 0.72^{*}$ & NS & 91 & $(42)$ \\
\hline & & & & & & & Cases 2: $1.32 \pm 1.69^{\star}$ & & & \\
\hline & & & & & & & Control: $1.17 \pm 0.54^{*}$ & & & \\
\hline \multirow[t]{2}{*}{ Ishikawa, 2013} & Japan & 24 & $7.9 \pm 2.8$ & 58 & $6.5 \pm 1.7$ & 4 & Cases 1: $15.4^{\#}$ & 0.022 & 100 & $(51)$ \\
\hline & & & & & & & Cases 2: 7.0\# & & & \\
\hline \multirow[t]{2}{*}{ Gupta-Malhotra, 2009} & USA & 28 & $20.9 \pm 6.0$ & 68 & $16 \pm 6$ & 0 & Cases: $0.24^{\star}$ & 0.118 & 36 & (54) \\
\hline & & & & & & & Control: $0.20^{*}$ & & & \\
\hline \multirow[t]{2}{*}{ Niboshi, 2008} & Japan & 35 & $27.0 \pm 4.2$ & 46 & $24.1 \pm 4.5$ & 9 & Cases 0: $0.153 \pm 0.32^{*}$ & $<0.05$ & NM & (5) \\
\hline & & & & & & & Control: $0.035 \pm 0.05^{\star}$ & & & \\
\hline \multirow[t]{2}{*}{ Borzutzky, 2008} & Chile & 11 & $10.6 \pm 2.0$ & 64 & $8.1 \pm 3.6$ & 1 & Cases: $0.23 \pm 0.3^{\star}$ & 0.045 & 100 & $(60)$ \\
\hline & & & & & & & Control: $0.05 \pm 0.03^{\star}$ & & & \\
\hline \multirow[t]{2}{*}{ Dalla Pozza, 2007} & Germany & 20 & $12.1 \pm 4.7$ & 60 & $4.1 \pm 3.6$ & NM & Cases 1: $14.0 \pm 6.2^{\#}$ & $<0.05$ & 100 & $(57)$ \\
\hline & & & & & & & Cases 2: $3.0 \pm 3.9^{\#}$ & & & \\
\hline
\end{tabular}

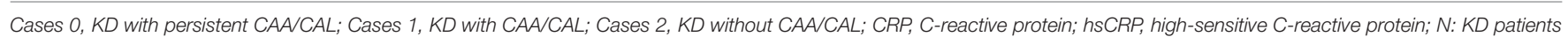

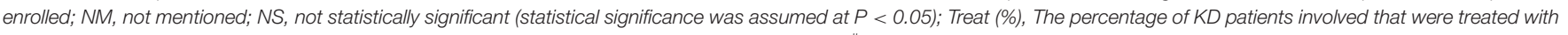
intravenous immunoglobulin (IVIG) infusion \pm aspirin at the time of diagnosis. "The value of hsCRP; \#The value of CRP. 
therapy is the first-line agent for primary prevention in patients at an increased risk for atherosclerotic events. Statins have beneficial effects on inflammation, endothelial function, oxidative stress (68-71). Although controversy remains on whether pathology of KD may have features of atherosclerosis, statins have been recently recommended for empirical therapy in $\mathrm{KD}$ patients with past or current aneurysms $(15,18)$ according to the AHA and JCS. Some studies $(10,72)$ reported that $\mathrm{KD}$ patients with aneurysms had shown statistically significant improvement in reductions in hsCRP and improved endothelial function after 3 months of statin therapy. In another small study, short-term statin therapy for 3 months seemed to significantly improve chronic vascular inflammation and endothelial dysfunction in children with $\mathrm{KD}$ with little to no adverse effects (73).

\section{Angiotensin II Receptor Blocker, Angiotensin Converting Enzyme Inhibitor}

Vascular stenosis is formed by intimal proliferation in $\mathrm{KD}$ patients, which is caused by the action of the renin-angiotensin system (RAS) in the vascular wall (18). Investigators found that angiotensin II (Ang II) has significant proinflammatory actions in the vascular wall, inducing inflammatory cytokines and adhesion molecules (74). It is hypothesized that RAS antagonists (ARB, ACEI) can prevent atherosclerosis by reducing vascular inflammation (75). They have also been shown to be protective against atherosclerotic CVD (76). JCS recommends ARB and ACEI for preventing coronary artery stenosis in KD patients with CAL (18).

\section{$\beta$-Blockers}

$\beta$-blockers have an essential role in the management of the atherosclerotic disease $(77,78)$ by inhibiting the sympathetic system, exhibiting antioxidant and anti-inflammation effects (79). Their roles have also been extended to the KD coronary disease. AHA 2017 guidelines recommend $\beta$-blockers be considered for $\mathrm{KD}$ patients with persistent large or giant aneurysms because they are at high risk of developing MI (15).

\section{REFERENCES}

1. Sosa T, Brower L, Divanovic A. Diagnosis and management of Kawasaki disease. JAMA Pediatr. (2019) 173:278-9. doi: 10.1001/jamapediatrics.2018.3307

2. Modesti AM, Plewa MC. Kawasaki disease. [Updated 2021 Feb 3]. In: StatPearls. Treasure Island, FL: StatPearls Publishing (2021).

3. Fukazawa R. Long-term prognosis of Kawasaki disease: increased cardiovascular risk? Curr Opin Pediatr. (2010) 22, 587-92. doi: 10.1097/MOP.0b013e32833e12f7

4. Ghelani SJ, Singh S, Manojkumar R. Endothelial dysfunction in a cohort of North Indian children with Kawasaki disease without overt coronary artery involvement. J Cardiol. (2009) 53:226-31. doi: 10.1016/j.jjcc.2008. 11.006

5. Niboshi A, Hamaoka K, Sakata K, Yamaguchi N. Endothelial dysfunction in adult patients with a history of Kawasaki disease. Eur J Pediatr. (2008) 167:189-96. doi: 10.1007/s00431-007-0452-9

6. Cheung YF, Wong SJ, Ho MH. Relationship between carotid intima-media thickness and arterial stiffness in children after Kawasaki disease. Arch Dis Child. (2007) 92:43-7. doi: 10.1136/adc.2006.096628

\section{SUMMARY}

Whether the long-term pathological vascular processes in patients with KD history are distinct vasculopathy or typical atherosclerosis features remains controversial. In this article, we reviewed the pathology of $\mathrm{KD}$ and its possible role in atherosclerosis development. The risk factors for atherosclerosis have also existed in patients with $\mathrm{KD}$ history. Upon reviewing the recent data regarding whether $\mathrm{KD}$ history predisposes patients to premature atherosclerosis, there was no conclusive consensus. However, timely diagnosis and treatment of $\mathrm{KD}$ is critical to prevent cardiovascular complications. In addition, consistent follow-up visits may be necessary. Counseling on lifestyle factors affecting atherosclerosis, including dyslipidemia, hypertension, smoking, and obesity, is an essential aspect of longterm management in all patients with a history of KD. Moreover, it may be wise to give pharmacotherapy empirically for $\mathrm{KD}$ patients with past or present aneurysms.

\section{AUTHOR CONTRIBUTIONS}

FC and Y-YZ: conceptualization. Y-YZ and SK: writing-original draft preparation. FC and MZ: writing-review and editing. FC: funding acquisition. All authors have read and agreed to the published version of the manuscript.

\section{FUNDING}

This research was supported by the Specially Appointed Medical Expert Project of Jiangsu Commission of Health (2019) and the Medical Science and Technique Foundation of Nanjing Health Commission (YKK19104).

\section{ACKNOWLEDGMENTS}

We thank Dr. Wang Ming-Wei, an associate professor from the Affiliated Hospital of Hangzhou Normal University, for critical reading of the manuscript.

7. Gupta A, Singh S, Gupta A, Suri D, Rohit M. Aortic stiffness studies in children with Kawasaki disease: preliminary results from a follow-up study from North India. Rheumatol Int. (2014) 34:1427-32. doi: 10.1007/s00296-0143000-8

8. Mitra A, Singh S, Devidayal, Khullar M. Serum lipids in north Indian children treated for kawasaki disease. Int Heart J. (2005) 46:811-7. doi: 10.1536/ihj.46.811

9. Cheung YF, O K, Woo CW, Armstrong S, Siow YL, Chow PC, et al. Oxidative stress in children late after Kawasaki disease: relationship with carotid atherosclerosis and stiffness. BMC Pediatr. (2008) 8:20. doi: 10.1186/1471-2431-8-20

10. Hamaoka A, Hamaoka K, Yahata T, Fujii M, Ozawa S, Toiyama K, et al. Effects of HMG-CoA reductase inhibitors on continuous post-inflammatory vascular remodeling late after Kawasaki disease. J Cardiol. (2010) 56:245-53. doi: $10.1016 / j . j j c c .2010 .06 .006$

11. Mitani Y, Sawada H, Hayakawa H, Aoki K, Ohashi H, Matsumura M, et al. Elevated levels of high-sensitivity C-reactive protein and serum amyloid-A late after Kawasaki disease: association between inflammation and late coronary sequelae in Kawasaki disease. Circulation. (2005) 111:38-43. doi: 10.1161/01.CIR.0000151311.38708.29 
12. Routhu SK, Singhal M, Jindal AK, Kumar V, Yadav AK, Singh S. Assessment of endothelial dysfunction in acute and convalescent phases of Kawasaki disease using automated edge detection software: a preliminary study from North India. J Clin Rheumatol. (2019). doi: 10.1097/RHU.0000000000 001233

13. Ishikawa $\mathrm{T}$, Seki $\mathrm{K}$. The association between oxidative stress and endothelial dysfunction in early childhood patients with Kawasaki disease. BMC Cardiovasc Disord. (2018) 18:30. doi: 10.1186/s12872-0180765-9

14. Newburger JW, Takahashi M, Gerber MA, Gewitz MH, Tani LY, Burns JC, et al. Diagnosis, treatment, and long-term management of Kawasaki disease: a statement for health professionals from the Committee on Rheumatic Fever, Endocarditis, Kawasaki Disease. Council on Cardiovascular Disease in the Young, American Heart Association. Pediatrics. (2004) 114:1708-33. doi: 10.1542/peds.2004-2182

15. McCrindle BW, Rowley AH, Newburger JW, Burns JC, Bolger AF, Gewitz $M$, et al. Diagnosis, treatment, and long-term management of Kawasaki disease: a scientific statement for health professionals from the American Heart Association. Circulation. (2017) 135:e927-e99. doi: 10.1161/CIR.0000000000000484

16. Rife E, Gedalia A. Kawasaki disease: an update. Curr Rheumatol Rep. (2020) 22:75. doi: 10.1007/s11926-020-00941-4

17. C. f. CM. Nation-wide Survey for Kawasaki Disease. Division of Public Health, Jichi Medical University. Available at: https://www.jichi.ac.jp/dph/inprogress/ kawasaki/ (accessed Feburary 25, 2020) (in Japanese).

18. Fukazawa R, Kobayashi J, Ayusawa M, Hamada H, Miura M, Mitani $\mathrm{Y}$, et al. JCS/JSCS 2020 guideline on diagnosis and management of cardiovascular sequelae in Kawasaki disease. Circ J. (2020) 84:1348-1407. doi: 10.1253/circj.CJ-19-1094

19. Holman RC, Belay ED, Christensen KY, Folkema AM, Steiner CA, Schonberger LB. Hospitalizations for Kawasaki syndrome among children in the United States, 1997-2007. Pediatr Infect Dis J. (2010) 29:483-8. doi: 10.1097/INF.0b013e3181cf8705

20. Toubiana J, Poirault C, Corsia A, Bajolle F, Fourgeaud J, Angoulvant F, et al. Kawasaki-like multisystem inflammatory syndrome in children during the covid-19 pandemic in Paris, France: prospective observational study. BMJ. (2020) 369:m2094. doi: 10.1136/bmj.m2094

21. Lima-Setta F, Magalhães-Barbosa MC, Rodrigues-Santos G, Figueiredo E, Jacques ML, Zeitel RS, et al. Multisystem inflammatory syndrome in children (MIS-C) during SARS-CoV-2 pandemic in Brazil: a multicenter, prospective cohort study. J Pediatr (Rio J). (2020). doi: 10.1016/j.jped.2020.10.008. [Epub ahead of print].

22. Belot A, Antona D, Renolleau S, Javouhey E, Hentgen V, Angoulvant F, et al. SARS-CoV-2-related paediatric inflammatory multisystem syndrome, an epidemiological study, France, 1 March to 17 May 2020. Euro Surveill. (2020) 25:2001010. doi: 10.2807/1560-7917.ES.2020.25.22.2001010

23. Almoosa ZA, Al Ameer HH, AlKadhem SM, Busaleh F, AlMuhanna FA, Kattih O. Multisystem inflammatory syndrome in children, the real disease of COVID-19 in pediatrics - a multicenter case series from Al-Ahsa, Saudi Arabia. Cureus. (2020) 12:e11064. doi: 10.7759/cureus.11064

24. Godfred-Cato S, Bryant B, Leung J, Oster ME, Conklin L, Abrams J, et al. COVID-19-Associated Multisystem Inflammatory Syndrome in Children United States, March-July. 2020. MMWR Morb Mortal Wkly Rep. (2020) 69:1074-80. doi: 10.15585/mmwr.mm6932e2

25. Verdoni L, Mazza A, Gervasoni A, Martelli L, Ruggeri M, Ciuffreda M, et al. An outbreak of severe Kawasaki-like disease at the Italian epicentre of the SARS-CoV-2 epidemic: an observational cohort study. Lancet. (2020) 395:1771-8. doi: 10.1016/S0140-6736(20)31103-X

26. Henderson LA, Canna SW, Friedman KG, Gorelik M, Lapidus SK, Bassiri H, et al. American College of Rheumatology Clinical Guidance for Multisystem Inflammatory Syndrome in Children associated with SARS-CoV-2 and hyperinflammation in pediatric COVID-19: version 2. Arthritis Rheumatol. (2021) 73:e13-29. doi: 10.1002/art.41454

27. D. Gustafsson. Oral direct thrombin inhibitors in clinical development. $J$ Intern Med. (2003) 254:322-34. doi: 10.1046/j.1365-2796.2003.0 1225.x

28. Rowley AH, Baker SC, Shulman ST, Rand KH, Tretiakova MS, Perlman EJ, et al. Ultrastructural, immunofluorescence, and RNA evidence support the hypothesis of a "new" virus associated with Kawasaki disease. J Infect Dis. (2011) 203:1021-30. doi: 10.1093/infdis/jiq136

29. Rowley AH, Shulman ST. The epidemiology and pathogenesis of Kawasaki disease. Front Pediatr. (2018) 6:374. doi: 10.3389/fped.2018.00374

30. Nagata S. Causes of Kawasaki disease-from past to present. Front Pediatr. (2019) 7:18. doi: 10.3389/fped.2019.00018

31. Matsubara T, Ichiyama T, Furukawa S. Immunological profile of peripheral blood lymphocytes and monocytes/macrophages in Kawasaki disease. Clin Exp Immunol. (2005) 141:381-7. doi: 10.1111/j.1365-2249.2005.02821.x

32. Katayama K, Matsubara T, Fujiwara M, Koga M, Furukawa S. CD14+CD16+ monocyte subpopulation in Kawasaki disease. Clin Exp Immunol. (2000) 121:566-70. doi: 10.1046/j.1365-2249.2000.01321.x

33. Ariga S, Koga M, Takahashi M, Ishihara T, Matsubara T, Furukawa S. Maturation of macrophages from peripheral blood monocytes in Kawasaki disease: immunocytochemical and immunoelectron microscopic study. Pathol Int. (2001) 51:257-63. doi: 10.1046/j.1440-1827.2001.01202.x

34. Burns JC, Glodé MP. Kawasaki syndrome. Lancet. (2004) 364:533-44. doi: 10.1016/S0140-6736(04)16814-1

35. Naoe S, Takahashi K, Masuda H, Tanaka N. Kawasaki disease. With particular emphasis on arterial lesions. Acta Pathol Jpn. (1991) 41:785-97. doi: 10.1111/j.1440-1827.1991.tb01620.x

36. Fukazawa R, Ogawa S. Long-term prognosis of patients with Kawasaki disease: at risk for future atherosclerosis? J Nippon Med Sch. (2009) 76:124-33. doi: 10.1272/jnms.76.124

37. Aloi M, Tromba L, Rizzo V, D’Arcangelo G, Dilillo A, Blasi S, et al. Aortic intima-media thickness as an early marker of atherosclerosis in children with inflammatory bowel disease. J Pediatr Gastroenterol Nutr. (2015) 61:41-6. doi: 10.1097/MPG.0000000000000771

38. Urbina EM, Williams RV, Alpert BS, Collins RT, Daniels SR, Hayman L, et al. Noninvasive assessment of subclinical atherosclerosis in children and adolescents: recommendations for standard assessment for clinical research: a scientific statement from the American Heart Association. Hypertension. (2009) 54:919-50. doi: 10.1161/HYPERTENSIONAHA.109.192639

39. Brunzell JD, Davidson M, Furberg CD, Goldberg RB, Howard BV, Stein $\mathrm{JH}$, et al. Lipoprotein management in patients with cardiometabolic risk: consensus statement from the American Diabetes Association and the American College of Cardiology Foundation. Diabetes Care. (2008) 31:81122. doi: $10.2337 / \mathrm{dc} 08-9018$

40. Di Angelantonio E, Sarwar N, Perry P, Kaptoge S, Ray KK, Thompson A, Wood AM, et al. Major lipids, apolipoproteins, and risk of vascular disease. JAMA. (2009) 302:1993-2000. doi: 10.1001/jama.2009.1619

41. Zhang H, Xu MG, Xie LJ, Huang M, Shen J, Xiao TT. Meta-analysis of risk factors associated with atherosclerosis in patients with Kawasaki disease. World J Pediatr. (2016) 12:308-13. doi: 10.1007/s12519-016-0023-0

42. Cho HJ, Yang SI, Kim KH, Kim JN, Kil HR. Cardiovascular risk factors of early atherosclerosis in school-aged children after Kawasaki disease. Korean J Pediatr. (2014) 57:217-21. doi: 10.3345/kjp.2014.57.5.217

43. Parihar M, Singh S, Vignesh P, Gupta A, Rohit M. Mid-term risk for subclinical atherosclerosis and chronic myocarditis in children with Kawasaki disease and transient coronary abnormalities. Pediatr Cardiol. (2017) 38:1123-32. doi: 10.1007/s00246-017-1626-5

44. Geovanini GR, Libby P. Atherosclerosis and inflammation: overview and updates. Clin Sci (Lond). (2018) 132:1243-52. doi: 10.1042/CS20180306

45. Meuwese MC, Stroes ES, Hazen SL, van Miert JN, Kuivenhoven JA, Schaub RG, et al. Serum myeloperoxidase levels are associated with the future risk of coronary artery disease in apparently healthy individuals: the EPICNorfolk Prospective Population Study. J Am Coll Cardiol. (2007) 50:159-65. doi: 10.1016/j.jacc.2007.03.033

46. Cheung YF, Yung TC, Tam SC, Ho MH, Chau AK. Novel and traditional cardiovascular risk factors in children after Kawasaki disease: implications for premature atherosclerosis. J Am Coll Cardiol. (2004) 43:120-4. doi: 10.1016/j.jacc.2003.08.030

47. McCrindle BW, McIntyre S, Kim C, Lin T, Adeli K. Are patients after Kawasaki disease at increased risk for accelerated atherosclerosis? J Pediatr. (2007) 151:244-8, 248.e1. doi: 10.1016/j.jpeds.2007.03.056

48. Greenland P, Abrams J, Aurigemma GP, Bond MG, Clark LT, Criqui $\mathrm{MH}$, et al. Prevention Conference V: beyond secondary prevention: identifying the high-risk patient for primary prevention: noninvasive tests of 
atherosclerotic burden: Writing Group III. Circulation. (2000) 101:E16-22. doi: 10.1161/01.CIR.101.1.e16

49. Gopalan K, Singh S, Vignesh P, Gupta A, Rohit M, Attri SV. Carotid intimamedia thickness and lipid profile in children with Kawasaki disease: a singlecenter follow-up study after a mean duration of 6.9 years. J Clin Rheumatol. (2018) 24:385-9. doi: 10.1097/RHU.0000000000000754

50. Chen KY, Zannino D, Curtis N, Cheung M, Burgner D. Increased aortic intima-media thickness following Kawasaki disease. Atherosclerosis. (2017) 260:75-80. doi: 10.1016/j.atherosclerosis.2017.03.022

51. Ishikawa $T$, Iwashima $S$. Endothelial dysfunction in children within 5 years after onset of Kawasaki disease. J Pediatr. (2013) 163:1117-21. doi: 10.1016/j.jpeds.2013.04.046

52. Meena RS, Rohit M, Gupta A, Singh S. Carotid intima-media thickness in children with Kawasaki disease. Rheumatol Int. (2014) 34:1117-21. doi: 10.1007/s00296-013-2820-2

53. Selamet Tierney ES, Gal D, Gauvreau K, Baker AL, Trevey S, O'Neill SR, Jaff MR, et al. Vascular health in Kawasaki disease. J Am Coll Cardiol. (2013) 62:1114-21. doi: 10.1016/j.jacc.2013.04.090

54. Gupta-Malhotra M, Gruber D, Abraham SS, Roman MJ, Zabriskie JB, Hudgins LC, et al. Atherosclerosis in survivors of Kawasaki disease. J Pediatr. (2009) 155:572-7. doi: 10.1016/j.jpeds.2009.04.054

55. Lee SJ, Ahn HM, You JH, Hong YM. Carotid intima-media thickness and pulse wave velocity after recovery from Kawasaki disease. Korean Circ J. (2009) 39:264-9. doi: 10.4070/kcj.2009.39.7.264

56. Noto N, Okada T, Karasawa K, Ayusawa M, Sumitomo N, Harada K, et al. Age-related acceleration of endothelial dysfunction and subclinical atherosclerosis in subjects with coronary artery lesions after Kawasaki disease. Pediatr Cardiol. (2009) 30:262-8. doi: 10.1007/s00246-008-9329-6

57. Dalla Pozza R, Bechtold S, Urschel S, Kozlik-Feldmann R, Netz H. Subclinical atherosclerosis, but normal autonomic function after Kawasaki disease. $J$ Pediatr. (2007) 151:239-43. doi: 10.1016/j.jpeds.2007.03.057

58. Watanabe M, Fukazawa R, Ogawa S, Ohkubo T, Abe M, Hashimoto K, et al. Virtual histology intravascular ultrasound evaluation of coronary artery lesions within 1 year and more than 10 years after the onset of Kawasaki disease. J Cardiol. (2020) 75:171-6. doi: 10.1016/j.jjcc.2019.06.015

59. Liu XQ, Huang GY, Liang XV, Ma XJ. Endothelial progenitor cells and arterial functions in the late convalescence period of Kawasaki disease. Acta Paediatr. (2009) 98:1355-9. doi: 10.1111/j.1651-2227.2009.01334.x

60. Borzutzky A, Gutiérrez M, Talesnik E, Godoy I, Kraus J, Hoyos R, et al. High sensitivity C-reactive protein and endothelial function in Chilean patients with history of Kawasaki disease. Clin Rheumatol. (2008) 27:845-50. doi: 10.1007/s10067-007-0808-6

61. Kato H, Sugimura T, Akagi T, Sato N, Hashino K, Maeno Y, et al. Long-term consequences of Kawasaki disease. A 10- to 21-year follow-up study of 594 patients. Circulation. (1996) 94:1379-85. doi: 10.1161/01.CIR.94.6.1379

62. Laurito M, Stazi A, Delogu AB, Milo M, Battipaglia I, Scalone G, et al. Endothelial and platelet function in children with previous Kawasaki disease. Angiology. (2014) 65:716-22. doi: 10.1177/0003319713502392

63. Lin J, Jain S, Sun X, Liu V, Sato YZ, Jimenez-Fernandez S, et al. Lipoprotein particle concentrations in children and adults following Kawasaki disease. $J$ Pediatr. (2014) 165:727-31. doi: 10.1016/j.jpeds.2014.06.017

64. Libby P. Inflammation in atherosclerosis. Arterioscler Thromb Vasc Biol. (2012) 32:2045-51. doi: 10.1161/ATVBAHA.108.179705

65. Ridker PM. Residual inflammatory risk: addressing the obverse side of the atherosclerosis prevention coin. Eur Heart J. (2016) 37:1720-2. doi: 10.1093/eurheartj/ehw024

66. Expert panel on integrated guidelines for cardiovascular health and risk reduction in children and adolescents: summary report. Pediatrics. (2011) 128(Suppl. 5):S213-56. doi: 10.1542/peds.2009-2107C

67. Grundy SM, Stone NJ, Bailey AL, Beam C, Birtcher KK, Blumenthal RS, et al. 2018 AHA/ACC/AACVPR/AAPA/ABC/ACPM/ADA/AGS/APhA/ ASPC/NLA/PCNA Guideline on the Management of Blood Cholesterol: a
Report of the American College of Cardiology/American Heart Association Task Force on Clinical Practice Guidelines. Circulation. (2019) 139:e1082e143. doi: 10.1016/j.jacc.2018.11.002

68. Schmidt-Lucke C, Fichtlscherer S, Rössig L, Kämper U, Dimmeler S. Improvement of endothelial damage and regeneration indexes in patients with coronary artery disease after 4 weeks of statin therapy. Atherosclerosis. (2010) 211:249-54. doi: 10.1016/j.atherosclerosis.2010. 02.007

69. Castejon R, Castañeda A, Sollet A, Mellor-Pita S, Tutor-Ureta P, JimenezOrtiz $\mathrm{C}$, et al. Short-term atorvastatin therapy improves arterial stiffness of middle-aged systemic lupus erythematosus patients with pathological pulse wave velocity. Lupus. (2017) 26:355-64. doi: 10.1177/09612033166 62719

70. Ruszkowski P, Masajtis-Zagajewska A, Nowicki M. Effects of combined statin and ACE inhibitor therapy on endothelial function and blood pressure in essential hypertension - a randomised double-blind, placebo controlled crossover study. J Renin Angiotensin Aldosterone Syst. (2019) 20:1470320319868890. doi: 10.1177/1470320319868890

71. Bekki M, Tahara N, Tahara A, Honda A, Igata S, Sugiyama Y, et al. Anti-inflammatory effect of statin in coronary aneurysms late after Kawasaki disease. J Nucl Cardiol. (2019) 26:671-3. doi: 10.1007/s12350-0181278-8

72. Duan C, Du ZD, Wang Y, Jia LQ. Effect of pravastatin on endothelial dysfunction in children with medium to giant coronary aneurysms due to Kawasaki disease. World J Pediatr. (2014) 10:232-7. doi: 10.1007/s12519-014-0498-5

73. Niedra E, Chahal N, Manlhiot C, Yeung RS, McCrindle BW. Atorvastatin safety in Kawasaki disease patients with coronary artery aneurysms. Pediatr Cardiol. (2014) 35:89-92. doi: 10.1007/s00246-013ss0746-9

74. Pacurari M, Kafoury R, Tchounwou PB, Ndebele K. The Renin-Angiotensinaldosterone system in vascular inflammation and remodeling. Int J Inflam. (2014) 2014:689360. doi: 10.1155/2014/689360

75. Fukuda D, Enomoto S, Nagai R, Sata M. Inhibition of reninangiotensin system attenuates periadventitial inflammation and reduces atherosclerotic lesion formation. Biomed Pharmacother. (2009) 63:754-61. doi: 10.1016/j.biopha.2009.02.006

76. Kaski JC, Fernandez-Berges D. Secondary prevention after acute myocardial infarction and coronary revascularisation: focus on Angiotensin converting enzyme inhibitors. Cardiovasc Drugs Ther. (2008) 22:185-91. doi: 10.1007/s10557-008-6097-8

77. Chen SJ, Tsui PF, Chuang YP, Chiang DM, Chen LW, Liu ST, et al. Carvedilol ameliorates experimental atherosclerosis by regulating cholesterol efflux and exosome functions. Int J Mol Sci. (2019) 20:5202. doi: 10.3390/ijms202 05202

78. Vrablík M, Tumová E. Atherosclerosis and beta-blockade: a forgotten option? Vnitr Lek. (2020) 65:795-801.

79. FeuersteinGZ, Ruffolo RR Jr. Carvedilol, a novel vasodilating beta-blocker with the potential for cardiovascular organ protection. Eur Heart J. (1996) 17(Suppl. B):24-9. doi: 10.1093/eurheartj/17.suppl_B.24

Conflict of Interest: The authors declare that the research was conducted in the absence of any commercial or financial relationships that could be construed as a potential conflict of interest.

Copyright (c) 2021 Zeng, Zhang, Ko and Chen. This is an open-access article distributed under the terms of the Creative Commons Attribution License (CC BY). The use, distribution or reproduction in other forums is permitted, provided the original author(s) and the copyright owner(s) are credited and that the original publication in this journal is cited, in accordance with accepted academic practice. No use, distribution or reproduction is permitted which does not comply with these terms. 